\title{
Stone-free rate with no major complication as a definition of success in percutaneous nephrolithotomy
}

\author{
Jorge Moreno-Palacios, ${ }^{1}$ Oswaldo José Avilés-Ibarra, ${ }^{1}$ Virgilio Agusto López-Samano, ${ }^{1}$ \\ Rodolfo Rivas-Ruiz, ${ }^{2}$ Juan Rodríguez-Silverio ${ }^{3}$ and Efraín Maldonado-Alcaraz ${ }^{1}$ \\ 'Instituto Mexicano del Seguro Social, Centro Médico Nacional Siglo XXI, Specialty Hospital; ${ }^{2}$ Instituto Mexicano del Seguro Social, Centro Médico \\ Nacional Siglo XXI, Health Research Coordination; ${ }^{3}$ Instituto Politécnico Nacional, Higher School of Medicine, Postgraduate Studies and Research \\ Section. Ciudad de México, Mexico
}

\begin{abstract}
Introduction: Success in percutaneous nephrolithotomy ( $P C N L)$ is defined as a stone-free status; however, major complications are highly common and have been reported as a secondary outcome. Objective: To propose a new definition of PCNL success that comprises a stone free rate without major complications and a risk scale to predict this outcome. Methods: Historical cohort of patients undergoing PCNL. The included variables were age, gender, urine culture, Charlson's comorbidity index $(\mathrm{CCl})$ and complex stones. Success was defined as a stone free status with or without Clavien grade $\leq 2$ complication; intermediate success: with stones, with or without Clavien grade $\leq 2$ complication; and failure: with or without stones with Clavien grade $\leq 2$ complication. Bivariate analysis was performed to identify which factors are associated with the outcome. The independent weight of each factor was calculated by multiple logistic regression analysis. Results: 568 procedures were included, $59 \%$ of which were in females. Median age was 49 years; $65 \%, 22 \%$ and $13 \%$ of cases were classified as success, intermediate success and failure, respectively. Female sex, positive urine culture, complex stones and severe CCI were associated with failure. Conclusions: The likelihood of success was directly proportional to the number of risk factors.
\end{abstract}

KEY WORDS: Kidney calculi. Percutaneous nephrolithotomy. Risk factor. Postoperative complications. Treatment outcomes.

\section{Introduction}

Nephrolithiasis has a worldwide incidence of $1 \%$ and affects 5 to $10 \%$ of the population in industrialized countries. ${ }^{1,2}$ Percutaneous nephrolithotomy (PCNL) is the procedure of choice for the resolution $>2 \mathrm{~cm}$ stones and, in selected cases, for stones smaller than these dimensions with particular anatomical localizations. ${ }^{3,4}$ PCNL is the second most practiced endourological procedure in the Mexican Institute of Social Security National Medical Center Siglo XXI Specialty Hospital.

Recently, PCNL success has been proposed to be defined as a stone-free status or as the presence of $<4 \mathrm{~mm}$ residual lithiasis, an outcome that is achieved in 76 to $95 \%$ of cases..$^{5-7}$ There are three scales to predict PCNL outcome: the Guy ${ }^{8}$ and the STONE$^{9}$ scales, which evaluate anatomical and stone characteristics of the compromised renal unit, and the nephrolithometric nomogram, ${ }^{10}$ which adds some clinical background data to its prediction. However, these scales are exclusively designed to predict the stone-free rate (SFR), with complications being left as secondary outcomes.

Complications in this procedure have been reported in 26 to $47 \%$ of cases, using the Clavien scale. ${ }^{11}$ The female gender (relative risk $[\mathrm{RR}]=2.6,95 \%$ $\mathrm{Cl}=1.1-5.9),{ }^{12}$ age $(\mathrm{OR}=1.024,95 \% \mathrm{Cl}=1.003-$ 1.04), ${ }^{13}$ an American Society of Anesthesiologists $(\mathrm{ASA})$ risk scale score $\geq 3(\mathrm{OR}=2.7, \mathrm{p}=0.001),{ }^{14}$ the presence of comorbidities $(\mathrm{OR}=4.4,95 \% \mathrm{Cl}=2.1-9),{ }^{15}$ positive urine culture $(\mathrm{OR}=2.5,95 \% \mathrm{Cl}=1.078-6)^{16}$ and complex stones $(\mathrm{OR}=4,95 \% \mathrm{Cl}=1.6-9.6)^{12}$ have been described to be preoperative clinical factors associated with complications. 
The purpose of this study is to present a new definition of PCNL success that includes the SFR and the presence of complications in conjunction, as well as to identify pre-surgical factors associated with this outcome.

\section{Method}

With approval of the local ethics committee, a historical cohort study was generated with patients diagnosed with renal lithiasis who underwent percutaneous surgery between January 2005 and September 2017. Patients with elective surgery were included and those with a percutaneous tract performed by the radiology department, without postoperative nephrostomy (tubeless), with bilateral approach and those who required multiple tracts were excluded. Patients with bilateral or recurrent lithiasis were regarded as having a new event if at least 90 days had elapsed between one procedure and the other.

Patient clinical characteristics were recorded, including age, gender, body mass index (BMI), ASA risk scale, presence of comorbidities, infection determined by urine culture or urinalysis, compromised renal unit and stone characteristics.

Age was grouped as $\geq 60$ and $<60$ years, BMl as normal (19-24.9), overweight (25-29.9) and obesity $(>30)$, ASA risk as $<3$ and $\geq 3$; comorbidities were grouped according to the Charlson comorbidity index $(\mathrm{CCl})$ in $<4$ and $\geq 5$. Presence of infection was considered only if there was a positive urine culture prior to surgery. Stones with a $>400 \mathrm{~mm}^{3}$ volume (width $x$ length $\times \mathrm{pi} \times 0.25)^{3,17}$ and those found in three or more collectors or in kidneys with anatomical alterations were considered to be complex.

Percutaneous access was performed by fluoroscopy in the prone position; after puncture of the desired calyx, an extra-rigid guide was placed. Dilatation of the tract was carried out with telescopic, serial and balloon dilators, according to the surgeon's preference. Nephroscopy and lithotripsy were carried out through an Amplatz sheath. Ballistic lithotripsy was used in all cases and the fragments were extracted with foreign body forceps. When the procedure was considered completed, a nephrostomy tube was placed under fluoroscopic guidance.

The presence of residual lithiasis ( $\geq 4 \mathrm{~mm}$ stone, clinically significant or need for subsequent surgical procedures) was regarded as an adverse outcome, in a plain abdominal $\mathrm{X}$-ray for radiopaque stones and a plain tomography for the radiolucent ones, as well as presence of complications within the first 30 days after the surgical procedure, which were grouped according to the proposal formulated by De la Rossette. ${ }^{11}$ The performance of a second intervention using the same nephrostomy orifice was regarded as the most serious complication. Complications were grouped into those that exclusively required medical management (Clavien $\leq 2$ ) and those that required invasive management, use of intensive therapy and those resulting in death (Clavien $>2$ ). To perform the analysis with a combined outcome assessing the presence of residual lithiasis and complications, three groups were formed:

- Success: no stones, without or with Clavien $\leq 2$ complication.

- Intermediate success: presence of stones, without or with Clavien $\leq 2$ complications.

- Failure: with or without stones, with Clavien $>2$ complication.

Taking into account the composite outcome and that there were five predictor variables, the calculation was made using the event per variable formula (10 subjects per variable to be assessed). The occurrence of $68 \%$ of successful events versus $11 \%$ of unfavorable events was considered. Five variables were analyzed; therefore, minimum sample size was 308 patients. ${ }^{18}$

\section{Statistical analysis}

A bivariate analysis was carried out, with relative risk (RR) and its $95 \%$ confidence interval $(\mathrm{Cl})$ being calculated in order to determine the preoperative variables that might predict the outcome. Subsequently, multiple logistic regression (MLR) was used to determine the specific weight of each variable.

Statistical significance for the bivariate analysis was considered at a $p$-value $<0.05$, and for the MLR, with $p<0.10$; the SPSS statistical program, version 22, was used.

\section{Results}

From January 2005 to September 2017, 590 firsttime PCNLs were performed; 568 procedures in 541 patients who met the inclusion criteria were included, out of which 337 (59 \%) were females. Median age was 49 years, 413 cases (73\%) had overweight or obesity, 94 (17\%) had an ASA risk $\geq 3$ and 218 (38\%) were cataloged with complex stones (Table 1). Overall, there were 416 cases (73.2 \%) free of stones. SFR was $80 \%$ in non-complex and $62 \%$ 
Table 1. Demographics of 565 patients who underwent percutaneous nephrolithotomy

\begin{tabular}{|c|c|c|}
\hline \multicolumn{3}{|l|}{ Characteristic } \\
\hline \multirow[t]{2}{*}{ Age (interquartile range) } & \multicolumn{2}{|c|}{49 years $(40-57)$} \\
\hline & $\mathbf{n}$ & $\%$ \\
\hline Males/females & $231 / 337$ & $41 / 59$ \\
\hline $\begin{array}{l}\text { Body mass index } \\
\quad \leq 25 \\
25-30 \\
>30\end{array}$ & $\begin{array}{l}155 \\
242 \\
171\end{array}$ & $\begin{array}{l}27 \\
43 \\
30\end{array}$ \\
\hline $\begin{array}{l}\text { Comorbidities } \\
\text { Single kidney } \\
\text { Diabetes mellitus } \\
\text { Hypertension } \\
\text { Heart disease } \\
\text { COPD } \\
\text { Kidney failure } \\
\text { Previous renal surgery }\end{array}$ & $\begin{array}{c}67 \\
121 \\
173 \\
20 \\
9 \\
71 \\
179\end{array}$ & $\begin{array}{c}12 \\
21 \\
30 \\
3.5 \\
1.5 \\
12.5 \\
31\end{array}$ \\
\hline $\begin{array}{l}\text { ASA risk } \\
\quad<3 \\
\geq 3\end{array}$ & $\begin{array}{c}474 \\
94\end{array}$ & $\begin{array}{l}83 \\
17\end{array}$ \\
\hline $\begin{array}{l}\text { Charlson comorbidity index } \\
\text { Mild } \\
\text { Moderate } \\
\text { Severe }\end{array}$ & $\begin{array}{l}468 \\
87 \\
40\end{array}$ & $\begin{array}{c}77 \\
15 \\
7\end{array}$ \\
\hline Positive urinalysis & 272 & 48 \\
\hline Positive urine culture & 175 & 30 \\
\hline $\begin{array}{l}\text { Affected kidney } \\
\text { Right } \\
\text { Left }\end{array}$ & $\begin{array}{l}284 \\
284\end{array}$ & $\begin{array}{l}50 \\
50\end{array}$ \\
\hline Complex stone & 219 & 38 \\
\hline
\end{tabular}

$\mathrm{COPD}=$ chronic obstructive pulmonary disease, $\mathrm{ASA}=$ American Society of Anesthesiologists.

for complex cases; $23 \%$ required a second surgical intervention; the most common indication was the presence of residual lithiasis, in $92 \% ; 223$ cases (39 $\%$ ) had at least one complication in both surgical times. Distribution according to the Clavien classification was 1, 89 (15\%); 2, 63 (11\%); 3A, 38 (6\%); 3B, $20(3.5 \%)$; 4A, six (1\%); 4B, three $(0.5 \%)$ and 5 , four $(0.7 \%)$.

According to the proposed new definition, there were $370(65 \%), 125(22 \%)$ and $73(13 \%)$ cases of success, intermediate success and failure, respectively.

The bivariate analysis showed that a positive urine culture $(\mathrm{RR}=2.1,95 \% \mathrm{Cl}=1.4-3.3, \mathrm{p}=0.00)$, a severe $\mathrm{CCl}(\mathrm{RR}=2.1,95 \% \mathrm{Cl}=1.4-3.3, \mathrm{p}=0.02)$ and complex stones $(\mathrm{RR}=2.6,95 \% \mathrm{Cl}=1.7-4.0, \mathrm{p}=0.00$ ) were associated with intermediate success; the female gender $(\mathrm{RR}=2.4,95 \% \mathrm{Cl}=1.3-4.2, \mathrm{p}=0.00)$, positive urine culture $(\mathrm{RR}=2.1,95 \% \mathrm{Cl}=1.4-3.3, \mathrm{p}=0.00)$, severe $\mathrm{CCl}(\mathrm{RR}=2.1,95 \% \mathrm{Cl}=1.1-3.9, \mathrm{p}=0.02)$ and complex stone (RR $=2.6,95 \% \mathrm{Cl}=1.7-4, \mathrm{p}=0.00)$ were associated with failure (Table 2).

With the aforementioned factors, an MLR was carried out, which showed that the independent factors for intermediate success were complex stones $(\mathrm{OR}=2.1,95 \% \mathrm{Cl}=1.4-3.2, \mathrm{p}=0.00)$, whereas for failure it was the female gender $(\mathrm{OR}=2.3,95 \%$ $\mathrm{Cl}=1.2-4.2, \mathrm{p}=0.00)$, positive urine culture $(\mathrm{OR}=$ $2.02,95 \% \mathrm{Cl}=1.1-3.4, \mathrm{p}=0.01)$, severe $\mathrm{CCl}(\mathrm{OR}=$ $3.8,95 \% \mathrm{Cl}=1.4-10, \mathrm{p}=0.00)$ and complex stone $(\mathrm{OR}=3.08,95 \% \mathrm{Cl}=1.8-5.2, \mathrm{p}=0.00)$ (Figure 1).

\section{Discussion}

PCNL has been established as the treatment of choice for renal stones larger than $2 \mathrm{~cm}$, given its high efficacy and rapid recovery in comparison with open surgery.

The SFR reported in our series demonstrated similar results to those in the global PCNL study conducted in 96 centers from all over the world and that recruited 5803 patients, in whom the success rate was $76 \%{ }^{5}$ It is important to consider that in the analyzed cases only pneumatic lithotripsy was used. The result for the stones regarded as complex (lithiasic load $>400 \mathrm{~mm}^{3}$ and in two or more collectors) was lower and most of them required a second surgical time, which agrees with the series where stone complexity scoring systems were evaluated: the higher the score, the lower the probability of SFR, although these systems are exclusively designed with the purpose to predict SFR. ${ }^{19}$

The most commonly reported variable was stonefree status; ${ }^{7}$ however, in addition to solving the problem (absence of stones), in order to have a successful surgical procedure it is important not to cause any major complication (Clavien $\geq 3$ ). Therefore, the definition of success we propose appears to us as a more real scenario in order for the situation of the patient who will undergo this procedure to be placed in context. Being an outcome composed of SFR and major complications, it occurred more frequently with respect to each factor independently evaluated.

Regarding complications in our study, we used the scale formulated by De la Rossette, ${ }^{11}$ specifically adapted for PCNL complications. In the series with the highest number of cases, the presence of complications was reported in 21.5 to $52 \%$; Clavien 1 and 2 complications were the most common, ${ }^{20}$ which are similar findings to those observed in this series. These 
Table 2. Bivariate analysis of factors associated with success and failure

\begin{tabular}{|c|c|c|c|c|c|c|c|c|c|c|}
\hline \multirow[t]{2}{*}{ Variable } & \multicolumn{2}{|c|}{$\begin{array}{l}\text { Success } \\
(n=370)\end{array}$} & \multicolumn{2}{|c|}{$\begin{array}{l}\text { Intermediate } \\
\text { success } \\
(n=125)\end{array}$} & \multirow[t]{2}{*}{$\begin{array}{c}\text { RR } \\
(95 \% \mathrm{Cl})\end{array}$} & \multirow[t]{2}{*}{$\mathbf{p}^{*}$} & \multicolumn{2}{|c|}{$\begin{array}{l}\text { Failure } \\
(n=73)\end{array}$} & \multirow[t]{2}{*}{$\begin{array}{c}\text { RR } \\
\text { (IC } 95 \%)\end{array}$} & \multirow[t]{2}{*}{$\mathbf{p}^{*}$} \\
\hline & $\mathrm{n}$ & $\%$ & $\mathrm{n}$ & $\%$ & & & $n$ & $\%$ & & \\
\hline \multicolumn{11}{|l|}{ Age (years) } \\
\hline$<60$ & 303 & 82 & 104 & 83 & 1 & 0.74 & 58 & 79 & 1 & 0.62 \\
\hline$\geq 60$ & 67 & 18 & 21 & 17 & $0.9(0.6-1.4)$ & & 15 & 21 & $1.1(0.6-1.9)$ & \\
\hline \multicolumn{11}{|l|}{ Gender } \\
\hline Male & 163 & 44 & 53 & 42 & 1 & 0.74 & 18 & 25 & 1 & 0.00 \\
\hline Female & 207 & 56 & 72 & 58 & $1.05(0.7-1.4)$ & & 55 & 75 & $2.4(1.3-4.2)$ & \\
\hline \multicolumn{11}{|c|}{ Urine culture } \\
\hline Negative & 274 & 74 & 81 & 65 & 1 & 0.04 & 38 & 52 & 1 & 0.00 \\
\hline Positive & 96 & 26 & 44 & 35 & $1.3(1.01-1.8)$ & & 35 & 48 & $2.1(1.4-3.3)$ & \\
\hline \multicolumn{11}{|c|}{ Charlson comorbidity index } \\
\hline $1-4$ & 354 & 96 & 114 & 91 & 1 & 0.05 & 65 & 89 & 1 & 0.02 \\
\hline$\geq 5$ & 16 & 4 & 11 & 9 & $1.6(1.03-2.7)$ & & 8 & 11 & $2.1(1.1-3.9)$ & \\
\hline \multicolumn{11}{|c|}{ Complex stone } \\
\hline No & 257 & 69 & 62 & 50 & 1 & 0.00 & 30 & 41 & 1 & 0.00 \\
\hline Yes & 113 & 31 & 63 & 50 & $1.8(1.3-2.4)$ & & 43 & 59 & $2.6(1.7-4.0)$ & \\
\hline
\end{tabular}

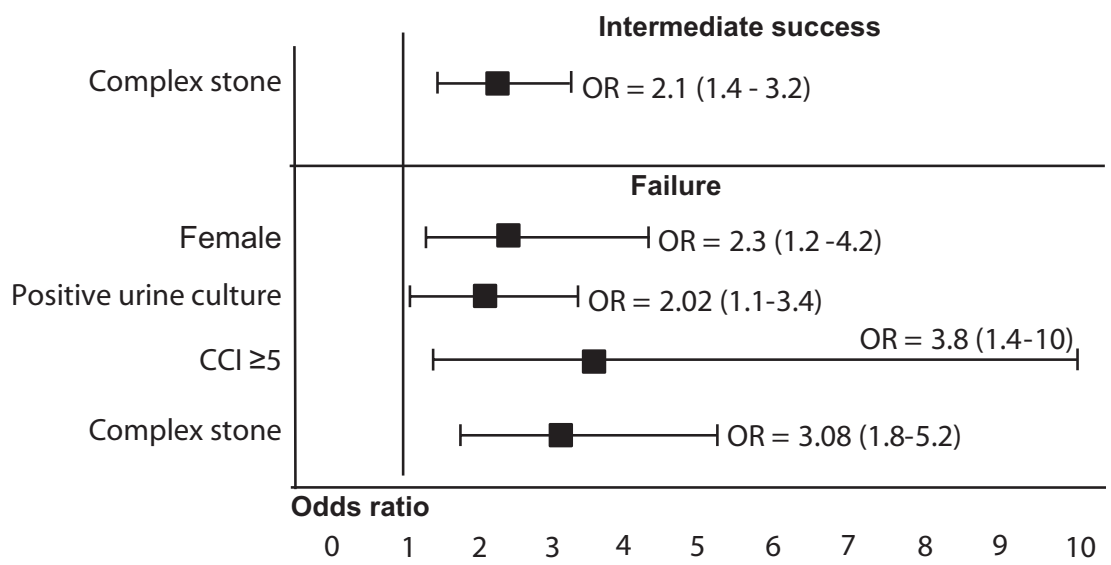

Figure 1. Multivariate analysis of independent risk factors associated with surgical failure. $\mathrm{CCl}=\mathrm{Charlson}$ comorbidity index, $\mathrm{OR}=\mathrm{odds}$ ratio.

occurred in part of the success or intermediate success groups, since their resolution only implies medical treatment adjustments. Regarding Clavien $>3$ complications (invasive management or death), their occurrence was slightly higher than that reported in previous series that did not use De la Rossette-proposed classification, which increased the number of patients with Clavien $3 \mathrm{~A}$ and $3 \mathrm{~B} .{ }^{20}$

The presence of patients with death secondary to surgery, classified as Clavien 5 , had been reported at between 0.1 and $0.03 \% .{ }^{21,22}$ In this series, there were four deaths $(0.7 \%)$, out of which two were secondary to septic shock, one due to upper Gl tract bleeding and one due to heart failure secondary to pneumonia.
In the series that have reported deaths the cause is not specified.

Selection and adequate preparation of patients prior to the surgical procedure is important in order to increase the likelihood of SFR and avoid complications. Several studies have tried to identify in an isolated way the risk factors that can predict the stone and complication-free rate; in this study, we assessed five risk factors to predict the composite outcome. Age $>60$ years has been associated with the presence of complications; ${ }^{13}$ however, we found no such association in our study, similarly as reported by Okeke et al. ${ }^{23}$

In comparison with the series with the largest number of patients, where approximately $46 \%$ of cases 
occurred in women, ${ }^{5,21}$ a larger proportion was observed in this study. The female gender was associated with failure; previously, we had reported the presence of greater complications in women, perhaps due to a higher number of complex cases, stones associated with infection and treatment delay. ${ }^{12,24}$ Positive urine culture (recorded in at least one of every three cases) has been associated with complications in patients undergoing PCNL. ${ }^{16,25}$ In the present work, it was an independent factor associated with failure.

The $\mathrm{CCl}$ has been used as a practical way to group comorbidities. ${ }^{26}$ Recently, we established that a severe $\mathrm{CCl}$ is associated with major complications. ${ }^{12}$ In this study, a severe $\mathrm{CCl}$ represented at least twice the risk of failure.

The classification of stone complexity has been studied in recent years exclusively to predict the SFR. ${ }^{8-10}$ In the STONE scale, as described by Okhunov et al., the lithiasic load (main factor used in our classification of complex stones) is the factor that most importantly contributes to the absence of a SFR. ${ }^{9}$ The series with the highest number of cases only classified the stones as being staghorn or not in the risk analysis; complications were identified to be associated with staghorn stones. ${ }^{27}$ In the present series, this was the only factor that was independently associated in the intermediate success and failure groups.

To presurgically identify patients with the aforementioned characteristics, doctor-patient communication should be improved in order to lay out more realistic expectations about the implications of percutaneous surgery, to modify the type of treatments and to better prepare the patient in order for him/her to be in the best possible conditions prior to undergoing the procedure.

This study has limitations. Most series consider SFR as an absence of stones; however, most articles refer to extracorporeal lithotripsy as the therapeutic modality. ${ }^{28}$ For this outcome, we considered $\leq 4 \mathrm{~mm}$, clinically non-significant stones (non-obstructive lithiasis associated with sterile urine), evaluated by means of a plain abdomen X-ray in a 3-week period for radiopaque stones and with plain abdominal tomography for the radiolucent ones. In our setting, the use of plain abdominal tomography to assess all cases would be extremely expensive.

The analyzed cohort is based on information that comes exclusively from medical records, and prospective studies are therefore required in order to establish the risk factors that can determine the prognosis of patients undergoing this surgery.

\section{Conclusions}

Nephrolithotomy is a safe and effective procedure for the resolution of kidney stones. The definition of success as SFR without major complication represents a more critical outcome in patients undergoing PCNL.

The female gender, positive urine culture, severe $\mathrm{CCl}$ and complex stones were factors associated with failure.

Adequate selection and preparation of patients for this procedure will increase the rate of success and avoid the occurrence of cases with residual lithiasis and major complications.

\section{References}

1. Bartoletti R, Cai T, Mondaini N, Melone F, Travaglini F, Carini M, et al. Epidemiology and risk factors in urolithiasis. Urol Int. 2007;79:3-7.

2. Ramello A, Vitale $C$, Marangella M. Epidemiology of nephrolithiasis. J Nephrol. 2000;13:S45-S50.

3. Türk C, Petrik A, Sarica K, Seitz C, Straub M, Traxer O, et al. EAU Guidelines on Urolithiasis. Países Bajos: European Association of Urology; 2010.

4. Pradere B, Doizi S, Proietti S, Brachlow J, Traxer O. Evaluation of guidelines for surgical management of urolithiasis. J Urol. 2018;199:1267-1271.

5. De la Rosette J, Assimos D, Desai M, Gutierrez J, Lingeman J, Scarpa R, et al. The Clinical Research Office of the Endourological Society Percutaneous Nephrolithotomy Global Study: indications, complications, and outcomes in 5803 patients. J Endourol. 2011;25:11-17.

6. Bryniarski P, Paradysz A, Zyczkowski M, Kupilas A, Nowakowski K, Bogacki R. A randomized controlled study to analyze the safety and efficacy of percutaneous nephrolithotripsy and retrograde intrarenal surgery in the management of renal stones more than $2 \mathrm{~cm}$ in diameter. J Endourol. 2012;26:52-57.

7. Opondo D, Gravas S, Joyce A, Pearle M, Matsuda T, Sun YH, et al. Standardization of patient outcomes reporting in percutaneous nephrolithotomy. J Endourol. 2014;28:767-774.

8. Thomas K, Smith NC, Hegarty N, Glass JM. The Guy's stone score: grading the complexity of percutaneous nephrolithotomy procedures. Urology. 2011;78:277-281.

9. Okhunov Z, Friedlander JI, George AK, Duty BD, Moreira DM, Srinivasan AK, et al. S.T.O.N.E. nephrolithometry: novel surgical classification system for kidney calculi. Urology. 2013;81:1154-1159.

10. Smith A, Averch TD, Shahrour K, Opondo D, Daels FP, Labate G, et al. A nephrolithometric nomogram to predict treatment success of percutaneous nephrolithotomy. J Urol. 2013;190:149-156.

11. De la Rosette JJ, Opondo D, Daels FP, Giusti G, Serrano A, Kandasami SV, et al. Categorisation of complications and validation of the Clavien score for percutaneous nephrolithotomy. Eur Urol. 2012;62:246-255.

12. Moreno-Palacios J, Maldonado-Alcaraz E, Montoya-Martínez G, Rivas-Ruiz R, Cedillo-Lopez U, Okhunov Z, et al. Prognostic factors of morbidity in patients undergoing percutaneous nephrolithotomy. J Endourol. 2014;28:1078-1084.

13. Olvera-Posada D, Tailly T, Alenezi H, Violette PD, Nott L, Denstedt JD, et al. Risk factors for postoperative complications of percutaneous nephrolithotomy at a tertiary referral center. J Urol. 2015;194:1646-1651.

14. Labate G, Modi P, Timoney A, Cormio L, Zhang X, Louie M, et al. The percutaneous nephrolithotomy global study: classification of complications. J Endourol. 2011;25:1275-1280.

15. Unsal A, Resorlu B, Atmaca AF, Diri A, Goktug HN, Can CE, et al. Prediction of morbidity and mortality after percutaneous nephrolithotomy by using the Charlson Comorbidity Index. Urology. 2012;79:55-60.

16. Rivera M, Viers B, Cockerill $P$, Agarwal D, Mehta R, Krambeck A Pre- and postoperative predictors of infection-related complications in patients undergoing percutaneous nephrolithotomy. J Endourol. 2016; 30:982-986 
17. Tiselius HG, Andersson A. Stone burden in an average Swedish population of stone formers requiring active stone removal: how can the stone size be estimated in the clinical routine? Eur Urol. 2003;43:275-281.

18. Peduzzi P, Concato J, Kemper E, Holford TR, Feinstein AR. A simulation study of the number of events per variable in logistic regression analysis. J Clin Epidemiol. 1996;49:1373-1379.

19. Labadie K, Okhunov Z, Akhavein A, Moreira DM, Moreno-Palacios J, Del-Junco $\mathrm{M}$, et al. Evaluation and comparison of urolithiasis scoring systems used in percutaneous kidney stone surgery. J Urol. 2015;193:154-159.

20. Seitz C, Desai M, Häcker A, Hakenberg OW, Liatsikos E, Nagele U, et al. Incidence, prevention, and management of complications following percutaneous nephrolitholapaxy. Eur Urol. 2012;61:146-158.

21. Tefekli A, Ali Karadag M, Tepeler K, Sari E, Berberoglu Y, Baykal M et al. Classification of percutaneous nephrolithotomy complications using the modified clavien grading system: looking for a standard. Eur Urol. 2008;53:184-190.

22. De la Rosette JJ, Zuazu JR, Tsakiris P, Elsakka AM, Zudaire JJ, Laguna MP, et al. Prognostic factors and percutaneous nephrolithotomy morbidity: a multivariate analysis of a contemporary series using the Clavien classification. J Urol. 2008;180:2489-2493.
23. Okeke Z, Smith AD, Labate G, D'Addessi A, Venkatesh R, Assimos D, et al. Prospective comparison of outcomes of percutaneous nephrolithotomy in elderly patients versus younger patients. J Endourol. 2012; 26:996-1001.

24. Frenk J, Gómez-Dantés O, Langer A. A comprehensive approach to women's health: lessons from the Mexican health reform. BMC Womens Health. 2012;12:42.

25. Gutierrez J, Smith A, Geavlete P, Shah H, Kural AR, De-Sio M, et al. Urinary tract infections and post-operative fever in percutaneous nephrolithotomy. World J Urol. 2013;31:1135-1140.

26. Resorlu B, Diri A, Atmaca AF, Tuygun C, Oztuna D, Bozkurt OF, et al. Can we avoid percutaneous nephrolithotomy in high-risk elderly patients using the Charlson comorbidity index? Urology. 2012;79:1042-1047.

27. Desai M, De Lisa A, Turna B, Rioja J, Walfridsson H, D'Addessi A, et al. The clinical research office of the endourological society percutaneous nephrolithotomy global study: staghorn versus nonstaghorn stones. J Endourol. 2011;25:1263-1268.

28. Deters LA, Jumper CM, Steinberg PL, Pais VM. Evaluating the definition of "stone free status" in contemporary urologic literature. Clin nephrol. 2011;76:354-357. 